\title{
Social processes promoting the adaptive capacity of rangeland managers to achieve resilience in the Karoo, South Africa
}

\author{
Ancois Carien de Villiers ${ }^{\mathrm{a},}{ }^{,}$, Karen J. Esler ${ }^{\mathrm{a}}$, Andrew T. Knight ${ }^{\mathrm{b}, \mathrm{c}}$ \\ ${ }^{a}$ Department of Conservation Ecology and Entomology, Stellenbosch University, Private Bag X1, Matieland 7602, South Africa \\ b Department of Life Sciences, Imperial College London, Silwood Park Campus, Buckhurst Road, Ascot, Berkshire SL5 7PY, United Kingdom \\ ${ }^{\mathrm{c}}$ Department of Botany, Nelson Mandela Metropolitan University, P.O. Box 77000, Port Elizabeth, South Africa
}

\section{A R T I C L E I N F O}

\section{Article history:}

Received 26 January 2014

Received in revised form

5 August 2014

Accepted 10 August 2014

Available online 2 September 2014

\section{Keywords:}

Adaptive management

Holistic management

Social networks

\begin{abstract}
A B S T R A C T
There is a recognized need to find working examples of structures that transfer the abstract concept of resilience to practical action for land management. Holistic Management ${ }^{\mathrm{TM}}$ is a decision-making framework promoting an adaptive land management across semi-arid and arid rangelands. We determined if Holistic Management ${ }^{\mathrm{TM}}$ promoted adaptive capacity among land managers in comparison to conventional management approaches within the context of the Karoo rangeland, South Africa. An Adaptive Capacity Index was developed which quantified the extent to which practices of land managers were aligned with six key traits of adaptive capacity. Data were collected through face-to-face interviews with 20 self-defined Holistic Management ${ }^{\mathrm{TM}}$ land managers and 20 self-defined non-Holistic Management $^{\mathrm{TM}}$ land managers. Social capital amongst land managers was explored using a social network analysis. Holistic Management ${ }^{\mathrm{TM}}$ land managers demonstrated higher adaptive capacity and greater participation in study groups. Holistic Management ${ }^{\mathrm{TM}}$ therefore appears to be a working example of a land management framework that promotes adaptive capacity of land managers in semi-arid to arid rangelands. Holistic Management ${ }^{\mathrm{TM}}$ may connect individual decision-makers to collective decisionmaking through social learning networks in the form of study groups. These study groups are thought to promote learning and innovation, which is key for implementing adaptive management.
\end{abstract}

() 2014 Elsevier Ltd. All rights reserved.

\section{Introduction}

Increasing regularity and severity of shocks to social-ecological systems (SES) have been partly attributed to the traditional command-and-control approach to management (Gunderson, 2000; Berkes et al., 2003; Walker and Salt, 2006). In this context, "sustainability" has been interpreted as the ability to produce a maximum sustainable yield of a specific product over a specified period of time, while suppressing disturbances to prevent "complications" (Berkes et al., 2003). The limitations of command-andcontrol approaches have been recognized (Berkes et al., 2003).

SES comprise complex dynamic interactions of interdependent, non-linear relationships between human societies and ecosystems (Berkes et al., 2003). Command-and-control approaches aim to maintain a single constant SES state of equilibrium. However, SES

\footnotetext{
* Corresponding author. Tel.: +27 (0)21 808 3304/4775; fax: +27 (0)21 808 4821/ 4807.

E-mail addresses: devilliersancois@gmail.com, ancoisdevil@gmail.com
} (A. Carien de Villiers). naturally shift through multiple states of stability (Holling, 1973). Single-state management has driven degradation and hence sustainability of SES by suppressing their inherent elasticity in response to shocks (Gunderson, 2000). This increases the risk of SES shifting into new less favourable stable states. Consequently, command-and-control approaches hamper resilience - the ability of SES to rebound to a previous stability state (Holling, 1973).

Managers are encouraged to maintain the resilience of SES by developing adaptive capacity (Walker and Salt, 2006). Adaptive capacity is the active management of resilience. It is a social, ecological and economic process manifesting the ability to adjust to erratic, fluctuating conditions by reducing detrimental impacts while taking full advantage of available options (Berkes et al., 2003; Walker and Salt, 2006). Accordingly, the importance of building and maintaining adaptive capacity has received considerable attention (Carpenter and Brock, 2008).

Despite the apparent value to the management of SES (Walker and Salt, 2006), the concepts of resilience (Gunderson and Holling, 2002) and adaptive management (Holling, 1978) are still vigorously debated within academic literature. Developing effective operational models that apply these concepts is a major 
challenge. Resilience is a highly complex concept and is difficult to relate to practical action (Schwarz et al., 2011). Likewise, adaptive capacity is context specific and changes according to local conditions, scale and perceptions (Pelling et al., 2008). Schwarz et al. (2011) pointed out that there is a need for the "development and field-testing of robust and measurable indices of resilience" and, consequently, adaptive capacity.

Determining a set of recognized characteristics of adaptive capacity could contribute to the application of related concepts by developing ways to assess the level of adaptability in communities. This would help to determine if a system is truly adapting by focusing on long term sustainability, or merely coping with an emphasis on short-term survival (Fabricius et al., 2007). Consequently, there is value in observing working examples of adaptive management frameworks that build adaptive capacity in real world situations.

Holistic Management ${ }^{\mathrm{TM}}$ (HM) is one such potential example. HM proposes that traditional reductionist management styles should shift to a more holistic approach (Savory and Butterfield, 1999). Others have supported such a paradigm shift (Odum, 1982; Naveh, 2000). In essence, HM is a decision-making framework emphasizing an holistic context for adaptive management (Savory and Butterfield, 1999) that promotes the management of whole systems and the management for change - key principles associated with resilience (Hosbach, 2012). HM encourages adaptive capacity through monitoring, active learning and inclusive decision-making (Savory and Butterfield, 1999). It is distinguished from other decision-making approaches by encouraging land managers to develop a written statement describing their personal aspirations. This statement is the holistic context ${ }^{\mathrm{TM}}$ (previously known as the "holistic goal" or holisticgoal ${ }^{\mathrm{TM}}$ ) which HM land managers use to guide their actions (Savory, 2012). It allows structured consideration of potential economic, social and ecological impacts of their actions across time and space.

Although HM is promoted for achieving adaptive land management, past research on HM has been limited. The majority of peer-reviewed studies focus on the controversial grazing principles associated with HM (Holechek et al., 2000; O'Connor et al., 2010). Briske et al. (2014) criticised the endorsement of the grazing practices advocated by $\mathrm{HM}$ in semi-arid and arid rangelands. However, the authors recognized and supported the adaptive management principles within the HM decision-making framework. The lack of research on topics beyond grazing principles has been recognized (Briske et al., 2011). Recent studies have linked HM to supporting resilience by facilitating the sustainable use of rangelands (Ferguson et al., 2013), fostering proactive and adaptive responses to challenges (McLachlan and Yestraue, 2009) and encouraging supportive social networks (Stinner et al., 1997; McLachlan and Yestraue, 2009).

Despite these encouraging findings, limited peer-reviewed studies have focused on this potential within the context of rangelands in southern Africa - although HM originated from this region (Savory and Butterfield, 1999). The rangelands of South Africa have been severely degraded specifically in the Karoo biome through poor land management practices (Keay-Bright and Boardman, 2007). The resilience of the Little Karoo, a sub-region of the Karoo, has been compromised to a point that major changes in land-use are impacting the local society, economy and ecology (O'Farrell et al., 2008). Consequently, it is essential for land managers within the Karoo to be able to assess and manage their adaptive capacity to promote SES resilience.

We tested whether the decision-making framework of HM promoted adaptive capacity in comparison to conventional approaches of land management within the Karoo rangelands. Our aims were to: $\mathrm{i}$ ) determine if $\mathrm{HM}$ is an adaptive management approach that promotes adaptive capacity; and ii) develop and apply methods for quantifying land manager's adaptive capacity. Cabell and Oelofse (2012) definition of resilience was adopted for this study: "the capacity to maintain the ability to feed and clothe people in the face of shocks while building the natural capital base upon which they depend and providing a livelihood for the people who make it function". Our objectives were to:

1) develop an Adaptive Capacity Index for quantifying the extent to which land managers demonstrate key traits associated with adaptive capacity;

2) compare land managers to determine if there is any notable distinction between self-defined HM land managers and nonHM land managers; and

3) analyse the social networks of land managers particularly in regards to their role in facilitating learning and innovation.

\section{Materials and methods}

\subsection{Study area}

Our study targeted land managers in the semi-arid rangelands surrounding the town of Graaff Reinet in the Eastern Cape province of South Africa The landscape is characterized by shrubby vegetation, erosive soils and is prone to stochastic events, notably periods of drought (Mucina et al., 2007). Livestock farming is the predominant land use with the majority of land managers applying a flexible land management approach as based on their own assessments and experience (Archer, 2004).

Historically, poor management practices have degraded the rangelands including localised overstocking and ploughing practises that damaged soil structure (Archer, 2004; Keay-Bright and Boardman, 2007). Fickle markets, increasing input costs and political marginalization have further compromised rural livelihoods (Nel et al., 2011). The consolidation of farms and a historical transition from predominantly livestock farming to ecotourism and game farming is increasingly common (Archer, 2004). Downscaling and land-use change associated with local farming activities have considerable implications for a region already characterised by poverty and welfare dependence (Nel et al., 2011).

\subsection{Approach}

\subsubsection{Understanding context}

O'Farrell et al. (2008) recently assessed the social-ecological resilience of the Klein Karoo - a nearby semi-arid region facing challenges similar to the study area - by applying the procedures of the Resilience Alliance, a network for interdisciplinary research to advance knowledge on SES (Resilience Alliance, 2007). The conclusions of this assessment were used as a contextual reference for this study, which is focused on the resilience assessment of individual land managers.

\subsubsection{Interview survey}

With the assistance of the local HM community, individuals practising $\mathrm{HM}$ and not practising HM were approached and invited to participate. If they consented, a snowball approach (Silverman, 2000) was adopted to identify further land managers, with preference given to neighbours. Land managers identified themselves as either HM or non-HM (NHM) land managers. The same methodological principles were applied across the HM and NHM groups. Consequently, if this snowball approach did strengthen the social network outcomes, this effect would have been equally influential across both groups of land managers. 
Table 1

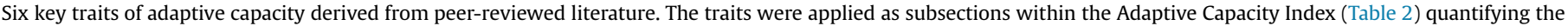
degree of adaptive capacity demonstrated by individual land managers.

\begin{tabular}{|c|c|c|}
\hline Trait & Description & Supporting references \\
\hline 1) Personal Control & $\begin{array}{l}\text { Proactive and empowered views on one's } \\
\text { own ability to facilitate adaptation. This included } \\
\text { information on the land managers' perceptions } \\
\text { of their impact in the community, self-reported } \\
\text { active community participation (e.g., notifying } \\
\text { authorities of local issues or participating in elections) } \\
\text { and how individuals scored on a Personal Control Sub-scale. }\end{array}$ & $\begin{array}{l}\text { (Brooks and Adger, 2004; Fabricius et al., 2007; } \\
\text { Brown et al., 2010) }\end{array}$ \\
\hline 2) Record Keeping \& Monitoring & $\begin{array}{l}\text { Continuous monitoring underpins adaptive management. } \\
\text { Land managers were asked to report if, and what, records } \\
\text { they kept and if they have structured grazing plans. } \\
\text { Evidence of adaptive planning was specifically sought. }\end{array}$ & $\begin{array}{l}\text { (Brooks and Adger, 2004; Fabricius et al., 2007; } \\
\text { Resilience Alliance, 2007) }\end{array}$ \\
\hline 3) Learning & $\begin{array}{l}\text { Learning is fundamental to adaptability. Land managers' } \\
\text { level of formal education and of actively seeking out } \\
\text { learning opportunities was quantified. }\end{array}$ & $\begin{array}{l}\text { (Resilience Alliance, 2007; Pelling et al., 2008; } \\
\text { Brown et al., 2010) }\end{array}$ \\
\hline 4) Innovation & $\begin{array}{l}\text { This subsection comprised two sub-scales: the Innovation } \\
\text { Sub-scale and Risk Aversion Sub-scale. These were } \\
\text { complemented with innovations demonstrated in past, } \\
\text { current or future activities. Differences were identified } \\
\text { between projects that were truly innovative (e.g., investigating } \\
\text { land-use options uncommon in the region) and projects that } \\
\text { simply improved or advanced established practices (e.g., refining } \\
\text { irrigation systems). }\end{array}$ & (Fabricius et al., 2007; Resilience Alliance, 2007) \\
\hline 5) Leadership and Group Participation & $\begin{array}{l}\text { The Leadership Sub-scale quantified the number of governing } \\
\text { positions a land manager held in the local community, whether } \\
\text { (s)he was identified by others as a "community leader", and the } \\
\text { number of groups an individual participated in. }\end{array}$ & $\begin{array}{l}\text { (Fabricius et al., 2007; Resilience Alliance, 2007; } \\
\text { Brown et al., 2010) }\end{array}$ \\
\hline 6) Diversity of income and land-use & $\begin{array}{l}\text { Land managers were asked to report the number of land-uses } \\
\text { they practiced and sources of income, which was believed to } \\
\text { indicate the readiness and willingness of a land manager to adapt. }\end{array}$ & (Fabricius et al., 2007; Resilience Alliance, 2007) \\
\hline
\end{tabular}

All land managers were provided a consent form, which stipulated their participation rights including confidentiality of their responses. Land managers indicated their preferred language of communication as Afrikaans or English and were interviewed during two excursions between November to December 2011 and June to July 2012. Interviews were semi-structured and face-to-face. Distinct but related interview protocols were customized for HM and NHM land managers (Appendix A and B). Interview protocols differed because some content was only relevant to HM land managers.

Prior to data collection, a pilot study was conducted which included: i) trialling the interview protocol with 10 volunteers; ii) a fact-finding excursion to meet representatives of the local HM community; and iii) qualitative interviews with people knowledgeable of the local history and context of HM within the study area and South Africa in general.

The interview protocols were constructed to provide data for the following three main topics: i) an adaptive capacity; ii) social networks; and iii) the dynamics and functioning of local study groups. Only a portion of the information gathered during the survey is relevant to the current study and will be reported on.

\subsubsection{Measuring adaptive capacity}

Cabell and Oelofse (2012) developed a set of behaviour-based indicators by reviewing literature on key traits most frequently associated with the resilience of social-ecological systems. If elements of these key traits are reported in the behaviour of land managers, it is assumed that adaptive capacity is present. Furthermore, a quantitative scoring process aids the comparison of adaptive capacity between individuals, because it provides a rudimentary measure of an intangible concept that itself cannot be directly quantified (Brown et al., 2010).

Following these examples, an Adaptive Capacity Index was developed to quantify and compare the adaptive capacity of HM and NHM land managers. The index was based on the Resilience
Alliance (2007) assessment approach in combination with a list of adaptive capacity traits compiled from literature (Table 1 ). The Adaptive Capacity Index included six traits of individual land managers relevant to their management activities (Table 2). Three of these traits included sub-scales: a Risk Aversion Sub-scale and Innovation Sub-scale (Innovation trait); a Leadership Sub-scale (Leadership and Group Participation trait); and a Personal Control Sub-scale (Personal Control trait).

Each of the six traits was quantified from responses to a set of items addressing self-reported attitudes, behaviours or perceptions relevant to specific traits. The response to each question was scored as " 0 " (regarded as deviating from the adaptive capacity trait), " 1 " (somewhat demonstrating the adaptive capacity trait) and "2" (demonstrates the adaptive capacity trait). The score for each question was then summed to give a total score for each trait.

The total scores of the six traits were given equal weight $(0.167)$ by dividing 1 by 6 . A final score including all the total scores of the traits was then summed for each land manager. Land managers were then categorised as "powerless spectator" (score $<0.40$ ), "coping actor" $(\geq 0.40$ to $<0.70)$ or "adaptive manager" (score $\geq 0.70$ ) per Fabricius et al. (2007).

Correlations were used to test for a relationship between the Adaptive Capacity Index and an HM Adoption Index for individual land managers (De Villiers, 2013). The HM Adoption Index quantified the extent to which land managers were aligned with the five main traits of HM: i) presence of a written holistic goal; ii) reports testing decisions; iii) demonstrated continuous learning; iv) demonstrated innovation; and v) application of holistic planned grazing (Savory and Butterfield, 1999). This index was developed following a similar approach to that used for the Adaptive Capacity Index, with scores allocated and weighted to land managers' responses. According to their scores, land managers were categorised as "non-Holistic" (score $<0.40)$, "semi-Holistic" $(\geq 0.40$ to $<0.70)$ and "true Holistic" (score $\geq 0.70$ ). 
Table 2

The structure of the scoring approach used to calculate Adaptive Capacity Index. The six traits each contributed a weight of 0.167 to the final score of each land manager.

\begin{tabular}{|c|c|c|c|}
\hline \multirow[t]{2}{*}{ Six traits } & \multicolumn{3}{|l|}{ Score } \\
\hline & 0 & 1 & 2 \\
\hline \multicolumn{4}{|l|}{ 1) Personal control } \\
\hline Perceived Community Impact & $\begin{array}{l}0=\text { unsure } \\
1=\text { no impact }\end{array}$ & $\begin{array}{l}2=\text { moderate impact; } \\
3=\text { impact }\end{array}$ & $\begin{array}{l}4=\text { big impact; } \\
5=\text { tremendous impact }\end{array}$ \\
\hline $\begin{array}{l}\text { Community Participation } \\
\text { (e.g., participation in local elections) }\end{array}$ & $1-3$ activities & 4-5 activities & $6-8$ activities \\
\hline Personal Control Sub-scale (score out of 100) & $\begin{array}{l}10 \text { to } 39 \\
\text { (Low personal } \\
\text { control) }\end{array}$ & $\begin{array}{l}40 \text { to } 69 \text { (Intermediate } \\
\text { personal control) }\end{array}$ & 70 to 100 (High personal control) \\
\hline \multicolumn{4}{|l|}{ 2) Record keeping \& monitoring } \\
\hline $\begin{array}{l}\text { Records kept (e.g., financial, rainfall, } \\
\text { livestock, grazing) }\end{array}$ & $0-2$ types & 3 types & 4 types \\
\hline Grazing \& Rangeland records & None & $\begin{array}{l}\text { Record livestock } \\
\text { count \& rotation }\end{array}$ & $\begin{array}{l}\text { Grazing charts, plans \& } \\
\text { budgeting grazing }\end{array}$ \\
\hline \multicolumn{4}{|l|}{ 3) Learning } \\
\hline Member of a study group & No & Formerly in a group & Yes \\
\hline Attended a workshop/seminar in the last 2 years & No & n.a. & Yes \\
\hline Sources of information (e.g., magazines, internet) & $1-2$ & $3-4$ & $5-6$ \\
\hline Tertiary Education & None & Diploma & Degree \\
\hline \multicolumn{4}{|l|}{ 4) Innovation } \\
\hline Innovation Sub-scale (score out of 100) & $\begin{array}{l}10 \text { to } 39 \text { (Low } \\
\text { innovation) }\end{array}$ & $\begin{array}{l}40 \text { to } 69 \text { (Intermediate } \\
\text { innovation) }\end{array}$ & 70 to 100 (Highly innovative) \\
\hline Risk Aversion Sub-scale (score out of 100 ) & $\begin{array}{l}70 \text { to } 100 \text { (High } \\
\text { risk aversion) }\end{array}$ & $\begin{array}{l}40 \text { to } 69 \text { (Intermediate } \\
\text { risk aversion) }\end{array}$ & 10 to 39 (Low risk aversion) \\
\hline Future Innovation & None & Development & Novel \\
\hline Current Innovation & None & Development & Novel \\
\hline Past Innovation & None & Development & Novel \\
\hline \multicolumn{4}{|l|}{ 5) Leadership and group participation } \\
\hline Leadership Sub-scale (score out of 100) & $\begin{array}{l}10 \text { to } 39 \text { (Low } \\
\text { leadership) }\end{array}$ & $\begin{array}{l}40 \text { to } 69 \text { (Intermediate } \\
\text { leadership) }\end{array}$ & 70 to 100 (High leadership) \\
\hline Identified by others as a community leader & 0 nominations & $<10$ nominations & $\geq 10$ nominations \\
\hline Highest level of leadership positions & None & Council position & Chairman \\
\hline Number of leadership positions & 0 & $1-2$ & $>2$ \\
\hline Number of groups of which a member & $0-2$ & $3-6$ & $\geq 7$ \\
\hline \multicolumn{4}{|l|}{ 6) Diversity of income } \\
\hline No. of land-use activities & 1 & 2 & $>2$ \\
\hline No. of agricultural income sources & 1 & 2 & $>2$ \\
\hline Off-farm or non-agricultural income & Only agricultural & Off-farm investments & $\begin{array}{l}\text { Non-agricultural business } \\
\text { (e.g. eco-tourism) }\end{array}$ \\
\hline
\end{tabular}

\subsubsection{Social networks}

Each land manager was provided with the list of interviewed land managers and asked to describe their relationship with each individual, specify whom they would approach for advice and whom they would call in a time of crisis.

The connections between land managers were mapped using the Pajek social network analysis software (De Nooy et al., 2005). Pajek is a freeware programme that can be used to analyse and visualise various networks including collaboration and connections among stakeholders. Three networks were mapped: i) all land managers; ii) only HM land managers; and iii) only NHM land managers. Of particular interest was the cohesion of the three networks regarding information exchange, support during a crisis and the level of familiarity amongst land managers. Cohesion, the number of ties within a network, was used to compare the connectivity of the different networks (De Nooy et al., 2005). Cohesion was measured as density (the percentage of all possible ties between individuals present in a network) and average degree (the mean number of ties of individuals to others within the network) (De Nooy et al., 2005).

\subsubsection{Study groups}

Land managers were asked if they were members of local study groups to provide insight into social learning networks. Study groups refer to any informal institution where members of the local community meet and engage in discussion for learning to improve their land management activities. Land managers in study groups were asked to describe the activities of these institutions, what topics were discussed, and of what value the study group was perceived to be to the land manager.

\subsubsection{Data analysis}

Data analysis included descriptive statistics and tests for significant differences between land managers' demographic information, their total Adaptive Capacity Index and the scores of the six sub-sections using T-tests and Pearson Chi-square tests were conducted using. Statistica 10 software (StatSoft, 2001).

Cronbach's $\alpha$ (Cronbach, 1951) was used to determine the internal consistency of the four sub-scales used within the Adaptive Capacity Index (i.e. the Risk Aversion Sub-scale, the Innovation Subscale, the Leadership Sub-scale and the Personal Control Sub-scale). Values of $\alpha>0.70$ were regarded as indicating acceptable internal consistency (Nunnally, 1978).

Two correlations were performed, firstly with the HM Adoption Index and Adaptive Capacity Index, and secondly with modified scores where overlapping data (including information demonstrating the innovation trait and some data regarding learning) were removed to avoid bias. The overlap was due to shared characteristics between the framework of HM and adaptive capacity, as HM is an adaptive management approach within a holistic context. 


\section{Results}

\subsection{Demographics}

Forty land managers participated, of whom 20 were self-defined HM land managers and 20 self-defined NHM land managers. The majority of land managers (90\% of both HM and NHM land managers) were the landowners and were responsible for the day-today farm management.

The demographic characteristics of HM and NHM land managers were similar. HM and NHM land managers had a similar age distribution ( $\mathrm{HM}$ mean $=47$ years; $\mathrm{NHM}$ mean $=46$ years $)$, annual financial turnover (mean of both HM and NHM land managers was approximately \$100 000-\$199 999), land management experience $(\mathrm{HM}$ mean $=20.9$ years; $\mathrm{NHM}$ mean $=17.5$ years $)$ and marital status (95\% of both HM and NHM land managers were married).

Primary home language $(p<0.05)$ and area of farmland under management $(p<0.05)$ were found to be significantly different. Seventy-five percent of HM land managers were English speaking, while $50 \%$ of NHM land managers were Afrikaans speakers. HM land managers generally managed smaller areas of land (HM mean $=5933.55$ ha; NHM mean $=8945.25$ ha).

\subsection{Scale development}

Three of the four sub-scales included in the Adaptive Capacity Index presented satisfactory degrees of internal consistency: the Risk Aversion Sub-scale $(\alpha=0.743)$, the Innovation Sub-scale $(\alpha=0.713)$ and the Leadership Sub-scale $(\alpha=0.8)$. The Personal Control Sub-scale $(\alpha=0.662)$ had a lower internal consistency. Consequently, only the Personal Control Sub-scale showed to be less effective in measuring the adaptive capacity trait specified for the sub-scale.

\subsection{Adaptive capacity}

The mean Adaptive Capacity Index for HM land managers was 0.758 (std dev. $=0.101$ ) and 0.598 for NHM land managers (std dev. $=0.122$ ). Although scores were distributed across a continuum, $80 \%$ of HM land managers were "adaptive managers" while $65 \%$ of NHM land managers were "coping actors" (Fig. 1). Two NHM land managers scored as "powerless spectators". As two separate groups, the scores of the HM and NHM land managers were significantly different $(p<0.01)$.

When comparing the sub-indexes of the Adaptive Capacity Index, no significant difference was found between HM and NHM land managers for personal control, leadership and group participation and diversity of income $(p>0.05)$. However, the differences between HM and NHM land managers regarding record keeping and monitoring were significant $(p<0.05)$ and highly significant for learning and innovation $(p<0.01)$.

To evaluate a possible relationship between the Adaptive Capacity Index and HM Adoption Index (which quantified to what extent land managers reported the five main managerial principles associated with $\mathrm{HM}$ ), a correlation was performed with the original scores of land managers $(r=0.754)$ and after removing data sections that overlapped $(r=0.531)$. Both correlations were highly significant $(p<0.001)$.

\subsection{Social networks}

Overall, the HM network had greater cohesion than the NHM network regarding requests for advice, support in a crisis, and friendship and family ties (Table 3). The density of the HM network was higher than both the NHM and the whole network. The HM network also had a higher average number of ties than the NHM network. The whole network had the most ties, as expected because the whole network included more land managers $(n=40)$ than the HM and NHM networks $(n=20)$.

The cohesion of the HM network was further supported by the number of HM land managers who knew (mean > 14) or had a close relationship (mean $>5$ ) with other HM land managers in comparison with lower scores amongst NHM land managers (Table 4). HM land managers had slightly more numerous family relations within the HM network (mean $>1$ ) than the average NHM land manager in the NHM network (mean $<1$ ).

\subsection{Study groups}

Study group membership was predominated by HM land managers. Only three NHM land managers reported being part of a study group or equivalent group (15\%), whilst $18 \mathrm{HM}$ land managers (90\%) reported being part of such an institution.

Seven study groups were identified - of which five identified themselves as HM groups. Study group membership ranged from four to nine individuals (mean $=6$ ). Members were predominantly livestock farmers, although two groups included local businessmen. HM study groups typically met on a quarterly basis, each member having an opportunity to host a meeting on their farm. All members are welcome to suggest topics for discussion, although the main focus of meetings were issues and challenges the host wished to discuss. Consequently, each member is provided an opportunity for a "think tank" on the challenges they are facing.

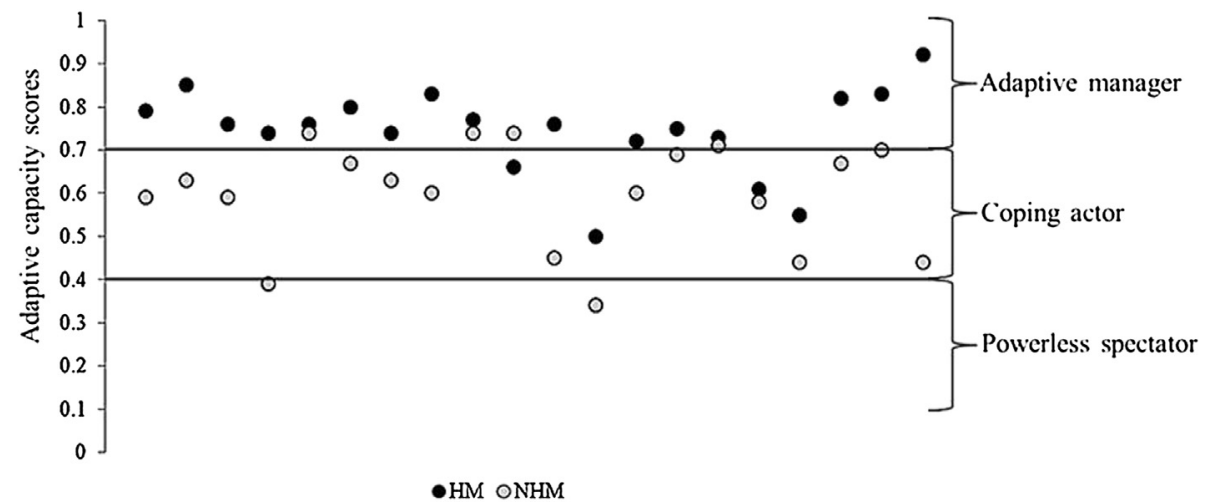

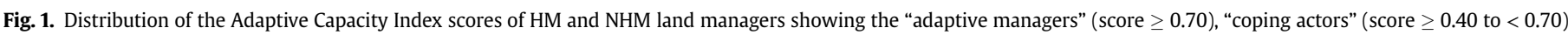
and "powerless spectators" (score < 0.40). 
Table 3

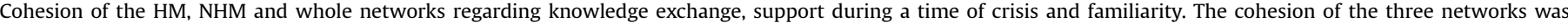

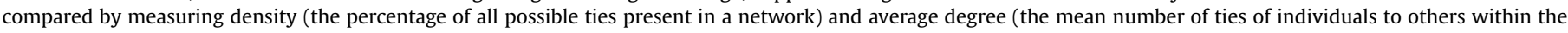
network).

\begin{tabular}{|c|c|c|c|c|c|c|}
\hline \multirow[t]{2}{*}{ Network } & \multicolumn{2}{|c|}{ Asking advice } & \multicolumn{2}{|c|}{ Support in crisis } & \multicolumn{2}{|c|}{ Family \& friends } \\
\hline & Density & Average degree & Density & Average degree & Density & Average degree \\
\hline Whole $(n=40)$ & 0.388 & $15($ std dev $=1.838)$ & 0.219 & $12.7($ std $\operatorname{dev}=5.857)$ & 0.224 & $8.75($ std dev $=4.928)$ \\
\hline $\mathrm{HM}(n=20)$ & 0.545 & $13($ std dev $=3.156)$ & 0.332 & $8.4($ std dev $=3.382)$ & 0.276 & $7.5($ std dev $=2.711)$ \\
\hline NHM $(n=20)$ & 0.308 & $8.5($ std dev $=2.924)$ & 0.168 & $4.8($ std $\mathrm{dev}=2.821)$ & 0.113 & $2.9($ std dev $=2.385)$ \\
\hline
\end{tabular}

At least $50 \%$ of respondents mentioned the following as major discussion topics during study group sessions: livelihoods (e.g., concerns with shale gas prospecting in the area, legislation affecting agriculture); social issues (e.g., labour relations, rural schools); agricultural activities (e.g., farming practices, livestock diseases); and strategic planning (e.g., local town future, inheritance arrangements for individual farms). Study group activities included comparing farm records, discussing local community, going on learning excursions to farms, and socializing, including family activities. Land managers specifically emphasize the value of these study groups as forums to exchange ideas and advice (100\% of 18 HM group members) and the groups' supportive role included references to friendship, encouragement and trust (67\% of $18 \mathrm{HM}$ group members).

\section{Discussion}

The Karoo's SES are highly susceptible to stochastic events including drought and fluctuations in international markets (Archer, 2004; Keay-Bright and Boardman, 2007), making land management highly challenging. To promote sustainability in regions during times of uncertainty, it is essential to implement land management approaches that foster adaptive capacity (Schwarz et al., 2011). Results of our study suggest that HM is one such approach.

\subsection{Adaptive capacity}

Few land managers presented a "powerless" level of adaptive capacity. The capricious circumstances of the Karoo have likely selected for land managers willing and able to implement effective adaptive management strategies, as demonstrated by the general entrepreneurial shift towards diversified land-use and income streams (Archer, 2004). In our study, both HM and NHM land managers demonstrated similar levels of diversification; however, adaptive capacity was generally higher with HM land managers. If the management approach of a land manager was aligned with the main traits of HM, the manager also tended to demonstrate a high adaptive capacity.

It is not clear whether HM specifically promotes adaptive behaviour or if it attracts resilient holistic thinkers (Sherren et al., 2012). General demographic characteristics and several

\section{Table 4}

The mean number of ties amongst land managers in the whole network, HM network and NHM network. Relationships were explored in regards to land managers knowing each other, being friends or family and only family.

\begin{tabular}{llll}
\hline \multirow{2}{*}{ Network } & \multicolumn{2}{l}{ Number of ties for each individual } \\
\cline { 2 - 4 } & Know about each other & Are family or friends & Are family \\
\hline Whole $(n=40)$ & 22.28 & 6.21 & 1.20 \\
HM $(n=20)$ & 14.25 & 5.25 & 1.25 \\
NHM $(n=20)$ & 9.25 & 1.95 & 0.35 \\
\hline
\end{tabular}

personality traits were not distinguishable between HM and NHM land managers. Overall, land managers had a similar distribution of leadership and sense of personal empowerment regarding social participation traits was presented. Although the Locus of Control Sub-scale had a weak internal consistency, it was still included as part of the Adaptive Capacity Index as it made a relatively small contribution to final scores and each land manager was assessed individually. Differences between NHM and HM land managers were, however, linked to planning, learning and innovation.

\subsection{Adaptive planning with grazing charts}

Monitoring, planning and re-planning are cited as foundational to HM (Savory and Butterfield, 1999). These traits are also key to adaptive management and to building adaptive capacity (Gunderson, 2000). The typical NHM land managers mostly reported only recording livestock numbers and rotations through camps (e.g. fenced pastures). HM land managers often applied elaborate grazing charts that included information on stocking rates, rainfall, ratings of the grazing quality of individual camps, when and why certain camps would not be available for livestock, and other often detailed information. These charts required input of continuous monitoring data and were often adjusted as conditions changed, which actively encourages land managers to keep records.

This HM approach requires considerable investment of time, effort and discipline and has been identified as a possible deterrent for HM adoption (Stinner et al., 1997). However, the majority of the current study's HM land managers actively used grazing charts. Indeed, some mentioned that they were essential when managing for drought by anticipating and budgeting grazing needs.

The HM approach appears to foster adaptive planning amongst land managers as noted by others (McLachlan and Yestraue, 2009; Sherren et al., 2012). Such a flexible planning structure could encourage creative problem solving, but structured and cohesive social networks amongst HM land managers have potential to enhance innovation and learning.

\subsection{Networks of learning and innovation}

Connectivity was comparatively high amongst HM land managers regarding knowledge exchange, support in a crisis and close relationships. Others have confirmed the important role of social networks amongst HM land managers for providing platforms to discuss anxieties and exchange ideas (Stinner et al., 1997; McLachlan and Yestraue, 2009). Family networks certainly played a notable role within the HM network and the snowball effect used in the methods possible amplified these values. However, the results of the current study could not be fully explained through the cohesion of family networks within the HM network, compared with the NHM network. What distinguished HM land managers from NHM land managers was the formation of study groups, a finding that concurs with previous studies (Keay-Bright and Boardman, 2007; McLachlan and Yestraue, 2009). 
Literature documented comparable land managers institutions, for example the Grasshoppers, a group of dairy farmers in the UK (Pelling et al., 2008) and Landcare, a grass roots initiative of Australian farmers that promotes sustainable natural resource management (Curtis, 2003). These institutions have similar characteristics to HM study groups, including regular meetings, sharing information and problems, learning excursions to farms and a strong group identity that unifies land managers (Curtis, 2003; Pelling et al., 2008; Compton and Beeton, 2012). These activities have been linked to enhancing trust, learning and innovation (Curtis, 2003; Pelling et al., 2008; Compton and Beeton, 2012) and also maintain a positive peer-pressure by members monitoring each other's progress (Grootaert and van Bastelaer, 2001). HM land managers in our study noted that they shared their goals and plans with study group members who then helped them to keep to these commitments. Land managers also reported primary benefits of a study group were the support and encouragement it provided. Study groups appear to support both the structural (i.e., networks facilitating information sharing and decision-making) and cognitive (i.e., trust and shared values) components of social capital (Grootaert and van Bastelaer, 2001). Social capital appears to be both a fundamental component and a product of these institutions (Curtis, 2003).

Despite the apparent benefits of study groups, there are several concerns. Building social capital requires investment of time and effort (Grootaert and van Bastelaer, 2001) which could discourage a land manager from joining a study group. This was pointed out by some HM and NHM land managers. Land managers also mentioned that because of the high level of trust required between members, it is very difficult for outsiders to join a study group. A contributing factor could also be the divergent grazing approaches amongst land managers - the grazing practices associated with HM are highly controversial in rangeland science (Holechek et al., 2000; Briske et al., 2011) and within some sections of the study community, which could discourage NHM land managers from engaging with HM study groups.

The effectiveness of social networks for adaptive capacity is dependent on the values of individuals. Compton and Beeton (2012) warn that strong bonding networks - specifically in reference to Landcare groups - could impair the flexibility of communities. Defined as "rigidity traps", such networks could promote resistance to shifting a system to a state that would be more beneficial for the whole community but one that a subset of network members may not support (Carpenter and Brock, 2008). Indeed, the preference for a specified resilient state is subjective (Walker and Salt, 2006; Fabricius et al., 2007).

\subsection{Moving forward}

No checklist of key adaptive capacity traits could ever comprehensively describe the level of resilience of a system, which is highly complex and probably unique. However, use of a scoring system provides a method for comparing the adaptive capacity of land managers (Brown et al., 2010).

The Adaptive Capacity Index used in the current study was not all-inclusive. Quantifications of ecological and economic resilience were excluded. Since these aspects of resilience are intimately related to social resilience (Fabricius et al., 2007), further research should holistically examine of these dimensions. The literature yields mixed sentiments regarding the ecological and economic benefits of HM both for (Ferguson et al., 2013) and against (Holechek et al., 2000; O'Connor et al., 2010). Recent research within the study area reported an unfavourable relationship between grazing management that applied HM and vegetation cover
- a possible indication of reduced ecological resilience (Archer, 2004; Keay-Bright and Boardman, 2007).

However, there is growing evidence that HM promotes social resilience (McLachlan and Yestraue, 2009; Sherren et al., 2012). If this relates to social networks as found in this study, then further development of study groups that facilitate learning for NHM land managers and other members of the local community should be promoted. Casual learning networks operating outside structured study groups seemed already well established amongst land managers as concluded from land managers' remarks and observations. Land managers claimed that they could approach almost any one of their neighbours for advice or for help in a time of crisis. This network can be further facilitated and structured by establishing study groups.

Building social networks as a foundation for strong social capital is essential for local communities facing considerable challenges. The study region is expected to continue experiencing political and economic marginalisation with dramatic demographic shifts as regional socio-economic centres such as Graaff Reinet increasingly urbanize and grow through depopulating of surrounding rural areas (Nel et al., 2011). Adaptive capacity is thus of considerable importance to the regional community. Study groups (especially those that engage members of various backgrounds and professions) could aid the process of connecting key role players, establishing common goals and values and diversify the exchange of ideas and information. This could be particularly relevant for previously disadvantaged emerging land managers as the land redistribution scheme in South Africa has been marred by controversies and severe shortages of capacity, knowledge and practical experience (Denison et al., 2009). Building social capital through the establishment of networks and collaborative associations could be invaluable to the viability of land redistribution (Denison et al., 2009).

\section{Conclusions}

HM appears to be a working example of a land management framework that promotes adaptive capacity within the context of agroecosystems. HM may connect individual decision-makers to collective decision-making through social learning networks in the form of study groups. This could support learning and innovation, which is key to building adaptive capacity.

\section{Acknowledgements}

Funding was provided by the Department of Science and Technology (DST) and managed by the National Research Foundation (NRF) of South Africa (Grant No: 74744) and the DST-NRF Centre of Excellence for Invasion Biology. The Department of Conservation Ecology and Entomology, Stellenbosch University, provided both support and ethical approval (Ref. no. DESC:DEVILAC/2012). Andrew Knight acknowledges the support of the Centre of Excellence in Environmental Decisions at the University of Queensland, Australia. Numerous individuals provided invaluable assistance to the author, specifically Dr. Justin Harvey (who assisted with statistical analyses), Jozua Lambrechts (who represented the Holistic Management ${ }^{\mathrm{TM}}$ community in South Africa) and both Prof Timm Hoffman and Dr Nicky Allsopp (who provided critical advice and guidance). This study would not have been possible without the considerable support and guidance offered by the Graaff Reinet, Aberdeen and Nieu Bethesda farming communities.

\section{Appendix A. Supplementary data}

Supplementary data related to this article can be found at http:// dx.doi.org/10.1016/j.jenvman.2014.08.005. 


\section{References}

Archer, E.R.M., 2004. Beyond the "climate versus grazing" impasse: using remote sensing to investigate the effects of grazing system choice on vegetation cover in the eastern Karoo. J. Arid Environ. 57, 381-408.

Berkes, F., Colding, J., Folke, C., 2003. Navigating Social-ecological Systems: Building Resilience for Complexity and Change. Cambridge University Press, Cambridge, UK.

Briske, D.D., Ash, A.J., Derner, J.D., Huntsinger, L., 2014. Commentary: a critical assessment of the policy endorsement for holistic management. Agric. Syst. 125, $50-53$.

Briske, D.D., Sayre, N.F., Huntsinger, L., Fernandez-Gimenez, M., Budd, B., Derner, J.D., 2011. Origin, persistence, and resolution of the rotational grazing debate: integrating human dimensions into rangeland research. Rangel. Ecol. Manag. 64, 325-334.

Brooks, N., Adger, W.N., 2004. Assessing and enhancing adaptive capacity. In: Lim, B. (Ed.), Adaptation Policy Framework. UN Development Programme, New York, USA, pp. 165-181.

Brown, P.R., Nelson, R., Jacobs, B., Kokic, P., Tracey, J., Ahmed, M., DeVoil, P., 2010. Enabling natural resource managers to self-assess their adaptive capacity. Agric. Syst. 103, 562-568.

Cabell, J.F., Oelofse, M., 2012. An indicator framework for assessing agroecosystem resilience. Ecol. Soc. 17, 18.

Carpenter, S.R., Brock, W.A., 2008. Adaptive capacity and traps. Ecol. Soc. 13, 40.

Compton, E., Beeton, R.J.S., 2012. An accidental outcome: social capital and its implications for landcare and the "status quo". J. Rural Stud. 28, 149-160.

Cronbach, L.J., 1951. Coefficient alpha and the internal structure of tests. Psychometrika 16, 297-334.

Curtis, A., 2003. Reflecting on the Landcare Experience: a Report Based on Information Held Within ABARE and BRS. Bureau of Rural Sciences, Canberra.

De Nooy, W., Mrvar, A., Batagelj, V., 2005. Exploring social network analysis with Pajek, first ed. Cambridge University Press, Cape Town, South Africa.

De Villiers, A.C., 2013. Towards Resilience: Differences in Management Practices Between Land Managers Adopting Conventional Approaches and Holistic Management (Unpublished MSc thesis). Stellenbosch University, Stellenbosch, South Africa.

Denison, J., Field, L., Wotshela, L., van Averbeke, W., Mutamba, M., Masika, P., Mayson, D., 2009. A Review of Experiences of Establishing Emerging Farmers in South Africa. Food and Agriculture Organization of the United Nations (FAO), Rome, Italy.

Fabricius, C., Folke, C., Cundill, G., Schultz, L., 2007. Powerless spectators, coping actors, and adaptive co-managers: a synthesis of the role of communities in ecosystem management. Ecol. Soc. 12, 29.

Ferguson, B.G., Diemont, S.A.W., Alfaro-Arguello, R., Martin, J.F., Nahed-Toral, J., Alvarez-Solís, D., Pinto-Ruíz, R., 2013. Sustainability of holistic and conventiona cattle ranching in the seasonally dry tropics of Chiapas, Mexico. Agric. Syst. 120 $38-48$.

Grootaert, C., van Bastelaer, T., 2001. Understanding and measuring social capital: a synthesis of findings and recommendations from the social capital intitiative. In: Social Capital Initiative Working Paper No.24. The World Bank, Washington, D.C.

Gunderson, L.H., 2000. Ecological resilience - in theory and application. Annu. Rev. Ecol. Syst. 31, 425-439.

Gunderson, L.H., Holling, C.S., 2002. Panarchy: understanding transformations in human and natural systems. Island Press, Washington, D.C.

Holechek, J.L., Gomes, H., Molinar, F., Galt, D., Valdez, R., 2000. Short-duration grazing: the facts in 1999. Rangelands 22, 18-22.
Holling, C.S., 1973. Resilience and stability of ecological systems. Annu. Rev. Ecol. Syst. 4, 1-23.

Holling, C.S., 1978. Adaptive Environmental Assessment and Management. Wiley, Chichester, UK.

Hosbach, A.C., 2012. Managing Land for Resilience: a Comparative Analysis of Conservation Planning and Holistic Management ${ }^{\circledR}$ (Unpublished MSc thesis). Humboldt State University, Arcata, USA.

Keay-Bright, J., Boardman, J., 2007. The influence of land management on soil erosion in the Sneeuberg Mountains, Central Karoo, South Africa. Land Degrad. Dev. 18, 423-439.

McLachlan, S.M., Yestraue, M., 2009. From the ground up: holistic management and grassroots rural adaptation to bovine spongiform encephalopathy across western Canada. Mitig. Adapt. Strat. Global Change 14, 299-316.

Mucina, L., Rutherford, M.C., Powrie, L.W., 2007. Vegetation Map of South Africa, Lesotho and Swaziland, 1:100 000, second ed. SANBI, Pretoria.

Naveh, Z., 2000. What is holistic landscape ecology? A conceptual introduction. Landsc. Urban Plan. 50, 7-26.

Nel, E., Taylor, B., Hill, T., Atkinson, D., 2011. Demographic and economic changes in small towns in South Africa's Karoo: looking from the inside out. Urban Forum 22, 395-410.

Nunnally, J., 1978. Psychometric Theory, second ed. McGraw-Hill, New York, USA.

O'Connor, T.G., Kuyler, P., Kirkman, K.P., Corcoran, B., 2010. Which grazing management practices are most appropriate for maintaining biodiversity in South African grassland? Afr. J. Range Forage Sci. 27, 67-76.

O'Farrell, P.J.O., Maitre, D.C., Gelderblom, C., Bonora, D., Hoffman, M.T., Reyers, B., 2008. Applying a resilience framework in the pursuit of sustainable land-use development in the Little Karoo, South Africa. In: Burns, Michael, Weaver, Alex (Eds.), Exploring Sustainability Science: a Southern African Perspective. African Sun Media, Stellenbosch, pp. 383-432.

Odum, W.E., 1982. Environmental degradation and the tyranny of small decisions. BioScience 32, 728-729.

Pelling, M., High, C., Dearing, J., Smith, D., 2008. Shadow spaces for social learning: a relational understanding of adaptive capacity to climate change within organisations. Environ. Plan. A 40, 867-884.

Resilience Alliance, 2007. Assessing Resilience in Social-ecological Systems: a Workbook for Scientists. Version 1.1 Draft for Testing and Evaluation. Accessed in May 2011. Available at: http://www.resalliance.org/.

Savory, A., 2012. A New Context, a New Framework. Savory Institute (SI). Accessed in November 2012. Available at: http://www.savoryinstitute.com.

Savory, A., Butterfield, J., 1999. Holistic Management: a New Framework for Decision Making, second ed. Island Press, Washington, DC.

Schwarz, A.-M., Béné, C., Bennett, G., Boso, D., Hilly, Z., Paul, C., Posala, R., Sibiti, S. Andrew, N., 2011. Vulnerability and resilience of remote rural communities to shocks and global changes: empirical analysis from Solomon Islands. Glob. Environ. Change 21, 1128-1140.

Sherren, K., Fischer, J., Fazey, I., 2012. Managing the grazing landscape: insights for agricultural adaptation from a mid-drought photo-elicitation study in the Australian sheep-wheat belt. Agric. Syst. 106, 72-83.

Silverman, D., 2000. Doing Qualitative Research: a Practical Handbook. Sage, London, UK.

StatSoft, I, 2001. Statistica: Data Analysis Software System.

Stinner, D.H., Stinner, B.R., Martsolf, E., 1997. Biodiversity as an organizing principle in agroecosystem management: case studies of holistic resource management practitioners in the USA. Agric. Ecosyst. Environ. 62, 199-213.

Walker, B.H., Salt, D., 2006. Resilience Thinking: Sustaining Ecosystems and People in a Changing World. Island Press, Washington, D.C., USA. 